\title{
Awareness, Condom Use Among Secondary School Students in Kenya
}

\author{
Mucugu, P. W. ${ }^{1}$, Githuku, N. $M^{2}$ \\ ${ }^{1,2}$ Maasai Mara University
}

\begin{abstract}
Risky sexual practices are rampant among adolescents in Kenya. The sexual practices include having multiple sexual partners and unprotected sexual intercourse. Consequences of risky sexual behaviour include early and unwanted pregnancies, abortions, school dropout, poor performance in school, infection with sexually transmitted diseases and HIV/AIDS. Secondary school students are in the category of adolescents because they are between the ages of 14-19 years. This study sought to assess the levels of awareness of condom use among secondary school students in the prevention of STDs in Bahati division of Nakuru North District. This study adopted an ex post facto research design. The target population included 12,319 students and 52 teacher counselors in the 52 secondary schools in the study area. A sample of 372 students and six teacher counsellors was selected from six schools. The schools were selected using stratified random sampling. The researcher purposively selected 36 mixed schools because girls and boys co-learn together. Data was collected through the administration of questionnaires. Data collected was processed and analyzed using descriptive and inferential statistics with the aid of the computer programme referred to as Statistical Package for Social Sciences (SPSS) version 11.5 for windows. One of the major findings was that the students expected the Guidance and Counselling departments in their schools to play a more assertive role in creating awareness on sexuality issues affecting them. Following the finding, the study recommended that the Guidance and Counselling programme be strengthened in the schools to enhance the awareness of sexual behavior and its related consequences.
\end{abstract}

Keywords: Awareness, Condom use, Sexually Transmitted Diseases, Students, Secondary Schools

\section{Introduction}

The population of the adolescents has been on the increase globally, representing 17 percent of the total population (World Health Organisation, 2012). Studies in Kenya indicate that there were more than 10.3 million adolescents in the country (Central Bureau of Statistics, 2001).

Public health attention in developing countries focused on adolescent reproductive health needs in response to increasing number of unwanted pregnancy for many years. However, in recent years, this attention has shifted to sexuality and reproductive health needs (Erulkar, Ettyang, Onoka, Nyaga \& Muyonga, 2003). High incidences of teenage pregnancies, abortions, sexually transmitted diseases (STDs) and Human Immuno Deficiency Virus and Acquired lmmuno Deficiency Syndrome (HIV/AIDS) have been reported the various studies.(Kenya Demographic and Health Survey,2003). The median age of sexual debut decreased from 18.8 years to 16.8 years (GoK, 2005; KDHS, 2003).Adolescent mothers are more likely to drop out of schools (FPAK, 2000). Secondary schools students are in their early adolescent stages where sexual desires and anxieties are high. Majority of them are tempted to engage in sexual activities that expose them to all the above risks (Anyango, 2005). African traditional societies had wellestablished systems of preparing young people for adult sexual roles and responsibilities. However, traditional systems have weakened and in some places, become extinct and have left adolescents poorly informed (World Bank, 2005). The high rates of STDs and pregnancy and abortions among students clearly illustrate the dangers of ignorance and lack of information (UNFPA, 1997)In realisation of this information gap, the Kenya Education Commission of 1964 (Ominde Report) and the Presidential Working Committee on Education and Training for this Decade and Beyond of 1988 (Kamunge Report) discussed students' reproductive health education and recommended that it be part of the Guidance and Counselling programme in learning, institutions.

The Commission of Inquiry into Education System in Kenya of 1999 (Koech Report) later on recommended that reproductive health education and even HIV/AIDS education be introduced in school curriculum in primary and secondary schools. HIV/AIDS education is now being taught as an integrated subject in primary and secondary schools.However, despite these government initiatives including establishment of Guidance and Counselling programme in secondary schools, there is relatively limited information about the level of awareness of students about contraceptive use in prevention of STDs. Secondary school students in Bahati division of Nakuru North District, as adolescents, have not been spared from the potential consequences of unsafe and unprotected sexual activities that expose them to STDs and pregnancy. This is in spite of the availability of contraceptive use to protect them. This necessitated the need to assess the level of awareness of condom use among secondary school students in the prevention of STDs .

\section{Methodology}

This study adopted an ex post facto research design. The study was conducted in Bahati Division in Nakuru North district in Rift Valley province. The target population for this study included all Form Two and Form Three students, and teacher counsellors from the 52 secondary schools in Bahati division. The 52 secondary schools had a total student population of 12,319 in the year 2007 (District Education Office ,Nakuru North 2007). The researcher selected six schools using random sampling and six teachers. The schools where boys and girls learning together were selected .From the sampling procedure ,the 372 students and 


\section{International Journal of Science and Research (IJSR) \\ ISSN (Online): 2319-7064}

Index Copernicus Value (2013): 6.14 | Impact Factor (2014): 5.611

the six counselors formed the sample size for this study. The data collected using two structured questionnaires were administered. One for students and another for teachers counselor was administered to the selected respondents.

Cronbach's Coefficient Alpha was computed for each instrument. Reliability coefficient of 0.72 was obtained which confirms that the reliability of the instruments was guaranteed .Data was analysed using descriptive and inferential statistics.

\section{Results}

There were 372 respondents from the selected secondary schools. Majority of the students $(95.1 \%)$ were between the age of 14 and 18 years. According to the education system in Kenya these figures are expected. Female students constituted $41.9 \%$ of the sample while male students constitute $58.1 \%$.

The students were asked to state their awareness on the use of any contraceptives in the school. An overwhelming majority $95 \%$ of the students had knowledge on at least one contraceptive among the many available on the market. The students were asked to state their awareness on whether their fellow students actively use condoms or not.

More than half the students (54\%) said they were aware of condom use among students in secondary schools. The results imply that majority of the students in secondary schools in Bahati division are sexually active and that, they also actively use condoms. Awareness, and use of condoms by students, raises another pertinent question; that of what the source of condoms was. The study therefore sought to establish the source of condoms available to students. The results show that the local retail shops were the most popular $(59 \%)$ source of condoms available to students. Medical facilities are a known source to $26 \%$ of the students. Other respondents said they could access condoms from home and entertainment spots. Only $4 \%$ of the students have no knowledge of where they would access condoms.Students were asked to state the source of information regarding contraceptives available to them. The results indicated that $21 \%$ of the students thought such information is available at the VCT centres. An almost equal proportion of $20 \%$ said that information could be provided by the Guidance and Counselling master or mistress. Incidentally $17 \%$ of the students surveyed had no idea of where they could obtain information concerning contraception methods.Results indicated that most students do not regard guardians as a good source of information on contraceptives. Students would rather get information from the VCT centers. Besides it is encouraging to find that a good proportion of the students are aware that such information can be obtained from Guidance and Counselling masters or mistresses. From the results, peers and the media would still play a significant role in providing information to students about use of contraceptives. The students were asked on their level of awareness on the correct practice in the use of condoms as contraceptives. Majority of the students knew correct practices in the use of condoms when engaging in sexual acts. Approximately $94 \%$ of the students surveyed agreed that it is necessary to check the expiry date of the condom before use. The students were asked about the effectiveness and reliability of condoms and $67.4 \%$ of the respondents said that condoms are not $100 \%$ effective and reliable. The students were found to have a high level of awareness on the correct use of condom.

The results showed that students expected the Guidance and Counselling departments in their schools to play a more assertive role in creating, awareness on contraceptive use and sexuality.

\section{Discussion}

Most secondary school students in Kenya are in the adolescent stage. They are between14-18years of age (GoK,2005).They undergo a lot of cognitive change and physical growth. The current national enrolment at the secondary schools level in Kenya is at $54 \%$ while that of girls is at $46 \%$ (GoK,1999). Peer influence has been proved to be a factor that contributes to early sexual activities (FHI, 2000).

Students, who were in their adolescent stage, were strongly influenced by their peers who felt that sexual activities are the "in-thing" (FHI,2000). Natural sexual desires and curiosity about sex was highly rated as influencing students towards engaging in sexual activities. This was indicated by $79.0 \%$ of the students, who agreed to the statement.

Majority of the students in secondary schools in Bahati division are sexually active and they also actively use condoms. In 2005, three quarters of sexually active $15-$ 19 year olds in Canada who had been with multiple partners in the past one year and /or who were not married or in a common law relationship reported using a condom the last time they had intercourse (Rotermann, 2008).

WHO (2002) findings show that students are the world's most poorly informed about the risks of HIV/AIDS means of transmission and their own venerability. Of all the sexually transmitted diseases HIV/AIDS is perhaps the most frightening of all since it has no cure (Schuller\&Barnett.,2000). The need for condoms is growing as HIV/AIDS and other sexually transmitted diseases infections spread. Making condoms more accessible and helping to overcome social and personal obstacles that limit their use are some of the widely advocated strategies that can be used to save lives lost due HIV/ AIDS. (United Management Consultants, 2000).

Sexual intercourse at an early age, having multiple sexual partners and unprotected sex put teens at the risk of sexually transmitted infections (STI) and unwanted pregnancy (Rotermann,2008). Therefore the younger the person becomes sexually active the longer they are at risk of unwanted pregnancy and of contracting a sexually transmitted infection (Rotermann, 2008). In Canada, $43 \%$ of teens aged 15-19 reported that they had sexually intercourse at least once by 2005 down from $47 \%$ in 1996 . This is in line with the trend in Kenya where the median age of sexual debut decreased from 18.8 years to 16.8 years according to KDHS (2003) and finding of the research.

\section{Volume 5 Issue 2, February 2016}




\section{International Journal of Science and Research (IJSR) \\ ISSN (Online): 2319-7064}

Index Copernicus Value (2013): 6.14 | Impact Factor (2014): 5.611

Behaviour change among the students is necessary in avoiding unhealthy sexual lifestyles. It concur with the fact that abstinence is the most effective way of preventing the spread to STDs including HIV/AIDS (Wienriech \& Benn, 2004).Many young people do not know the proper use of condoms. They prefer not to use them at all (Wienriech\& Benn, 2004). Students' knowledge on contraceptives as effective methods of STD prevention was limited to condoms as indicated by results of the research. The cost of a pack of condoms according to research is less than a dollar. In Ethiopia the cost differs from place to place and time; either day or night. However, many respondents that were involved in a survey considered the cost of a pack of condoms to be cheap. They pointed out that they faced little problems in getting the condoms (United Management Consultants, 2000).

In Ethiopia, the level of awareness according to the survey results showed that most people (88\%) know about the condom. However, only a third reported having ever used condoms. The recognition giving to the condom as a widely accepted mode of HIV/AIDS prevention by the community in Ethiopia, is in line with the fact that protection of self and partner from STI and HIV is the main reason for condom use (United Management Consultants, 2000).

Students showed awareness of various sexual issues (CBS, 2004 ).Young people need skills to deal with these pressure and expectations without putting themselves at risk (GoK, 2005). The Ministry of Education, Sports and Culture in Zimbabwe developed a policy that advocated for support of life skills and abstinence. There were arguments about condom break and leak. The church is reluctant to speak about the condom use to prevent infections limits young peoples' option (Ravai et al, 2003).Majority of teacher counsellors indicated that students were given information on sexuality and risks of early sexual activities. The information was passed on the students of all classes (F 1-4).

However, some students' have never sought information from the Guidance and Counselling Department. This was an indication that students were sensitive over issues of sexuality and contraceptives (CBS,2004). According to Ravai et al. (2003), adults should reconsider their moralizing concerning about young people's sexual activity and support real than limited choices with regards to adolescents' reproductive health.

The parents do not discuss adolescent reproductive health with their children instead they advise them on abstinence yet adolescents hide the condom for their parents (Ravai et al, 2003).

\section{Recommendation}

The study made the following recommendations in view of the above conclusions:

There is need to sensitize students on the dangers of early sexual activities through effective Guidance and Counseling programmes. This by enhancing life skills for students to help them overcome pressure and influences that make them engage in early sexual activities.
The study noted that peer pressure contributes immensely in influencing students towards engaging in early sexual behaviour.

Stakeholders in the education sector should formulate policies that will enhance responsible sexual behaviour among pupils and students to be in line with the millennium goals. The policies should aim at enhancing responsible sexual behaviour and improving enrollment in school of girls and boys.

\section{References}

[1] Central Bureau of Statistics - CBS (2004)Kenya Demographic and Health Survey 2003. Ministry of Health (MOH). Calverton Maryland: CBS, $\mathrm{MOH}$, and ORC Macro.

[2] Government of Kenya (2005).National Guidelines far Provision of Adolescent Youth-Friendly Services (YFS) in Kenya. Division of Reproductive Health, Ministry of Health. Nairobi: Government Printer.

[3] Kiragu,(2000).Country Analysis of Family Planning and HIV/AIDS : Kenya.

[4] MichelleRoterman(2008).Trends in teen sexual Behaviour and condom use.Componentsof Statistics CanadaCatalogue Health Reports

[5] RavaiMarindo, Steve Pearson\& John Beasterine, (2003). Condom use and Abstinence among unmarried Young people in Zimbabwe, which strategy, whose Agenda? Harare

[6] United Management Consultants (2000).Factors Affecting Accessibility and Utilization of Condom. The Futures of International, Ethiopia Policy Project, Addis Abba 